\section{D) Check for updates}

Cite this: Dalton Trans., 2018, 47, 7013

\title{
Selecting the spin crossover profile with controlled crystallization of mononuclear Fe(III) polymorphs $\uparrow$ t
}

\author{
Ana I. Vicente, (iD a ${ }^{a} b$ Liliana P. Ferreira, (iD b,c Maria de Deus Carvalho, ${ }^{a}$ \\ Vítor H. N. Rodrigues, ${ }^{c}$ Marinela M. Dîrtu, (D) d,e Yann Garcia, (D) ${ }^{d}$ \\ Maria José Calhorda (DD ${ }^{a, b}$ and Paulo N. Martinho (D)*a,b
}

\begin{abstract}
Two polymorphic species of the $\left[\mathrm{Fe}(5-\mathrm{Br} \text {-salEen })_{2}\right] \mathrm{ClO}_{4}$ compound were obtained, each of them being selectively recovered after evaporation of the solvent at a controlled rate. While polymorph $1 \mathrm{a}$ is formed during slow evaporation, fast evaporation favors polymorph $\mathbf{1 b}$. The importance of the evaporation rate was recognized after detailed studies of the reaction temperature, solvent evaporation rate and crystallization temperature effects. The complex in the new polymorphic form 1a showed an abrupt spin crossover at $172 \mathrm{~K}$ with a small $1 \mathrm{~K}$ hysteresis window and over a narrow $10 \mathrm{~K}$ range. ${ }^{57} \mathrm{Fe}$ Mössbauer spectroscopy and differential scanning calorimetry, complemented by X-ray studies for both the high-spin and lowspin forms, were used to further characterize the new polymorphic phase 1a. Both polymorphs are based on the same Fe(III) complex cation hydrogen bonded to the perchlorate anion. These units are loosely bound in the crystals via weak interactions. In the new polymorph 1a, the hydrogen bonds are stronger, while the weak hydrogen and halogen bonds, as well as $\pi-\pi$ stacking, create a cooperative network, not present in $\mathbf{1 b}$, responsible for the spin transition profile.
\end{abstract}

Received 18th January 2018, Accepted 18th April 2018

DOI: $10.1039 / c 8 d t 00227 d$ rsc.li/dalton ment in the crystal may lead to diverse SCO behaviors that can be analyzed in terms of intermolecular interactions. ${ }^{3}$ Polymorphism associated with SCO may help to understand the relative contribution of intra- and intermolecular interactions in the spin transition features and consequently to define strategies to obtain and isolate each polymorphic phase. ${ }^{4-6}$

Thermal spin conversion may drastically change between different polymorphs, going from a crossover (gradual spinstate conversion between high-spin (HS) and low-spin (LS)) to a first-order transition (discontinuous variation of the HS fraction). This has been observed for mononuclear Fe(II) complexes $^{7-10}$ with some cases where only one of the polymorphs shows a thermal switching. ${ }^{11-15}$

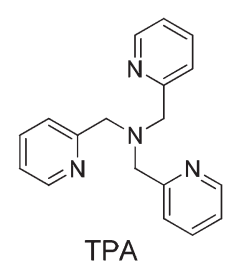

TPA

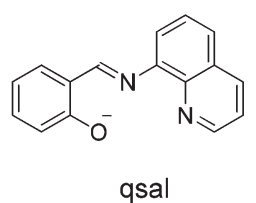<smiles>[O-]c1c(Cl)c(Cl)c(Cl)c(Cl)c1Cl</smiles><smiles>N/C(S)=N/N=C/c1ccccc1[O-]</smiles>

${ }^{a}$ Centro de Química e Bioquímica, Faculdade de Ciências, Universidade de Lisboa, Campo Grande, 1749-016 Lisboa, Portugal.E-mail: pnmartinho@fc.ul.pt ${ }^{b}$ Biosystems and Integrative Sciences Institute (BioISI), Faculdade de Ciências, Universidade de Lisboa, Campo Grande, 1749-016 Lisboa, Portugal ${ }^{c}$ Physics Department, University of Coimbra, 3004-516 Coimbra, Portugal (IMCN/MOST), Université Catholique de Louvain, Place L. Pasteur 1, 1348 Louvainla-Neuve, Belgium

${ }^{e}$ Faculty of Electrical Engineering and Computer Science \& MANSiD Research Center, Stefancel Mare University, Suceava, Romania

$\dagger$ In memory of Maria de Deus Carvalho.

\$Electronic supplementary information (ESI) available: Additional figures, tables and crystallographic data. CCDC 1579737 and 1579738. For ESI and crystallographic data in CIF or other electronic format see DOI: 10.1039/c8dt00227d

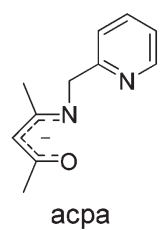

acpa 


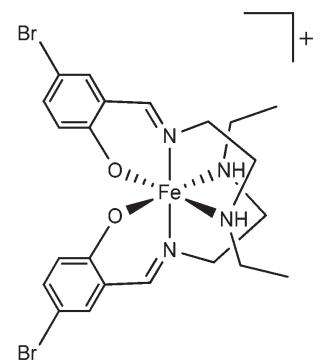

Scheme 1 Compound $\left[\mathrm{Fe}(5-\mathrm{Br} \text {-salEen })_{2}\right] \mathrm{ClO}_{4}$ studied in this work.

Polymorphism in Fe(III) SCO compounds is rare and the few reported cases displayed a wide range of magnetic profiles. Examples include [(TPA)Fe(TCC) $] \mathrm{PF}_{6},{ }^{4,16}$ with very similar profiles between polymorphs and $T_{1 / 2}$ differing by only $11 \mathrm{~K}$. $\left[\mathrm{Fe}-(\mathrm{acpa})_{2}\right] \mathrm{ClO}_{4}{ }^{17}$ shows two polymorphic phases where one is converted into the other after a structural phase transition. More interesting is $\left[\mathrm{Fe}(\mathrm{qsal})_{2}\right] \mathrm{I}_{3}{ }^{18}$ obtained as a mixture of two polymorphs with very different magnetic profiles. Three polymorphs of the $[\mathrm{Fe}(\mathrm{qsal})(\mathrm{thsa})]^{+}$complex ${ }^{5}$ are synthetically controlled by a desolvation procedure. Additionally, [(TPA)Fe (TCC) $] \mathrm{PF}_{6}$ polymorphs ${ }^{4}$ are selectively obtained through different crystallization solvent systems.

The polymorphic experimental control is still a rare event and only some examples show how each polymorph was selectively obtained. ${ }^{8,19,20}$ Indeed, the growth process involves the interplay between kinetics and thermodynamics to explain the formation of polymorphs related to the Ostwald's rule of stages ${ }^{21}$ according to which metastable forms can exist or coexist in the presence of more stable forms.

As part of our interest in Fe(III) SCO systems, ${ }^{22}$ we have recently found that a compound previously reported by us, $\left[\mathrm{Fe}(5 \text {-Br-salEen })_{2}\right] \mathrm{ClO}_{4}$ (Scheme 1$),{ }^{23}$ can be selectively obtained in two distinct polymorphic phases. In this work, the synthesis and characterization of the new polymorph and the attempts to both understand and selectively control their synthesis are fully explored.

\section{Experimental section}

\section{Materials}

$N$-Ethylethylenediamine, sodium perchlorate monohydrate, anhydrous iron(II) chloride, 5-bromobenzaldehyde and solvents were purchased and used without further purification. (Caution: perchlorate salts are notorious for explosiveness; thus, precautionary measures must be taken when handling them). $\left[\mathrm{Fe}(5-\mathrm{Br} \text {-salEen })_{2}\right] \mathrm{ClO}_{4}$ was synthesized as previously described. ${ }^{23}$ IR (KBr): $\nu_{\max } / \mathrm{cm}^{-1} 3249\left(\nu_{\mathrm{NH}}, \mathrm{m}\right), 3061\left(\nu_{\mathrm{CH}}, \mathrm{w}\right)$, $1630\left(\nu_{\mathrm{C}=\mathrm{N}}, \mathrm{s}\right), 1591\left(\delta_{\mathrm{C}=\mathrm{C}}, \mathrm{m}\right), 1301\left(\nu_{\mathrm{C}-\mathrm{N}}, \mathrm{s}\right), 1088\left(\nu_{\mathrm{ClO}_{4}}, \mathrm{~s}\right)$, $1064\left(\nu_{\mathrm{ClO}_{4}}, \mathrm{~s}\right), 624\left(\nu_{\mathrm{ClO}_{4}}, \mathrm{~s}\right)$. Anal. calcd for $\mathrm{C}_{22} \mathrm{H}_{28} \mathrm{Br}_{2} \mathrm{ClFeN}_{4} \mathrm{O}_{6}$ (\%): C, 37.99; H, 4.06; N, 8.05. Found: C, 37.92; H, 3.82; N, 7.84 .

\section{Instrumentation}

IR spectra were recorded on a PerkinElmer FTIR spectrophotometer. Microanalyses (C, H and N) were performed by elemental analysis service at the University of Vigo, Spain. Magnetization measurements as a function of temperature were performed using a SQUID magnetometer (Quantum Design MPMS). The curves were obtained at 1000 Oe for temperatures ranging from 10 to $370 \mathrm{~K}$ at different temperature variation rates (varying from $10 \mathrm{~K} \mathrm{~min}^{-1}$ to $0.1 \mathrm{~K} \mathrm{~min}^{-1}$ ) and the molar susceptibility $\left(\chi_{\mathrm{M}}\right)$ values were corrected for diamagnetism. ${ }^{57} \mathrm{Fe}$ Mössbauer spectra were recorded in the transmission mode at $290 \mathrm{~K}$ and at $78 \mathrm{~K}$ using a conventional constant-acceleration spectrometer and a $50 \mathrm{mCi}{ }^{57} \mathrm{Co}(\mathrm{Rh})$ source. The low temperature measurements were performed using a liquid nitrogen flow cryostat with a temperature stability of $\pm 0.5 \mathrm{~K}$. The velocity scale was calibrated using $\alpha$-Fe foil. The spectra were fitted to Lorentzian lines using the WinNormos software program, and the isomer shifts reported are relative to metallic $\alpha$-Fe at room temperature. Calorimetric measurements were carried out under a $\mathrm{He}(\mathrm{g})$ atmosphere using a Perkin-Elmer DSC Pyris instrument equipped with a cryostat and operating down to $113 \mathrm{~K}$. The purge gas was $\mathrm{N}_{2}(\mathrm{~g})$. Temperatures and enthalpies were calibrated over the temperature range 113-300 K using the solid/solid and liquid/solid transitions of pure cyclopentane (99\%, Acros). ${ }^{24}$ The calibration sample was introduced into an $\mathrm{Al}$ pan and hermetically sealed using an encapsulating press. The calibration was made at a scan rate of $10 \mathrm{~K} \mathrm{~min}^{-1}$. The characteristic temperatures, which were assigned to the crystal/crystal transitions of cyclopentane, were obtained by the extrapolation of the maximum peak temperatures. ${ }^{24}$ An empty $\mathrm{Al}$ pan, identical to the one used for the sample, was used as a reference to obtain a reliable baseline. The system produces or takes up energy in order to keep the temperature of the compound identical to the reference. This energy difference between two resistances (in $\mathrm{mW}$ ) is transformed by using PYRISTM DSC Software 7.0 in specific heat $C_{\mathrm{p}}$ $\left(\mathrm{J} \mathrm{mol}^{-1} \mathrm{~K}^{-1}\right)$. The DSC measurement of the sample was carried out at a scan rate of $10 \mathrm{~K} \mathrm{~min}^{-1}$, in warming and cooling modes. $30 \mathrm{mg}$ were encapsulated at room temperature in an aluminum pan and hermetically sealed. The sample was maintained at room temperature for $5 \mathrm{~min}$ in order to allow the system to equilibrate, and was further cooled down from 300 to $113 \mathrm{~K}$. The sample was maintained at $113 \mathrm{~K}$ for $5 \mathrm{~min}$ to reach equilibrium, followed by a similar scanning mode to that in cooling between $113 \mathrm{~K}$ and room temperature for which the data were recorded. The single crystal X-ray diffraction data were collected with monochromated Mo-K $\alpha$ radiation $(\lambda=0.71073 \AA)$ on a Bruker SMART Apex II diffractometer equipped a CCD area detector, CCDC 1579737 and 1579738.t Data reduction of each compound was carried out using the SAINT-NT software package. ${ }^{25}$ Multi-scan absorption corrections were applied to all raw intensity data using the SADABS program. ${ }^{26}$ The structures were solved by a combination of direct methods with subsequent difference Fourier syntheses and refined by full matrix least squares on $F_{2}$ using the 
SHELX-2014 programs. ${ }^{27}$ The $\mathrm{C}-\mathrm{H}$ and $\mathrm{N}-\mathrm{H}$ hydrogen atoms were inserted at geometrical positions with $U_{\text {iso }}$ proportional to $U_{\text {eq. }}$ of those they are attached. Figures of crystal packing diagrams were drawn with Mercury ${ }^{28}$ and PLATON software package. $^{29}$

\section{Results and discussion}

\section{X-ray studies}

$\left[\mathrm{Fe}(5-\mathrm{Br} \text {-salEen })_{2}\right] \mathrm{ClO}_{4}$ crystallizes using specific and different experimental conditions as two distinct polymorphs (hereafter denoted as $\mathbf{1 a}$ and $\mathbf{1 b}$ ). The latter was published elsewhere, ${ }^{23}$ and its structure was confirmed by single crystal X-ray diffraction. The new polymorph (1a) was obtained in the form of dark cubic crystals after evaporation of the solvent, similarly to $\mathbf{1 b} .^{23}$

The crystal structure of 1a, Fig. 1, was first determined at $105 \mathrm{~K}$ revealing that the compound crystallizes in the monoclinic space group $P 2_{1} / c$ with one cation and an ordered perchlorate anion. $\mathrm{Fe}-\mathrm{O}, \mathrm{Fe}-\mathrm{N}_{\mathrm{am}}$ and $\mathrm{Fe}-\mathrm{N}_{\mathrm{im}}$ bond lengths at this temperature are characteristic of a Fe(III) center in the low-spin (LS) state. ${ }^{30}$ On the other hand, $\mathbf{1 b}$ crystallizes in the orthorhombic space group $P b c n$ with one cation and an ordered perchlorate anion located on a crystallographic 2 -fold axis. ${ }^{23}$ The constraints imposed by the octahedral coordination geometry of Fe(III) and the planarity of the aromatic part of each tridentate ligand are responsible for the relative rigidity of the iron coordination sphere. Therefore, only a small conformational freedom is retained, mainly via the ethyl groups involved in weaker intramolecular interactions. Nevertheless, a distinct ligand arrangement of the complex cation in $\mathbf{1 a}$ and $\mathbf{1 b}$ is visible in Fig. 1, where they are drawn in similar perspectives. Overall, the angle between the ligand rings in 1a is more open than that in $\mathbf{1 b}$, as reflected by the $\alpha$ angles of $73.53(7)^{\circ}$ and 68.474(17) ${ }^{\circ}$, respectively, and other relevant intramolecular distances and angles shown in Table 1. The distance from C1 (terminal carbon of the ethyl group) to $\mathrm{Br} 1$ is a measure of the

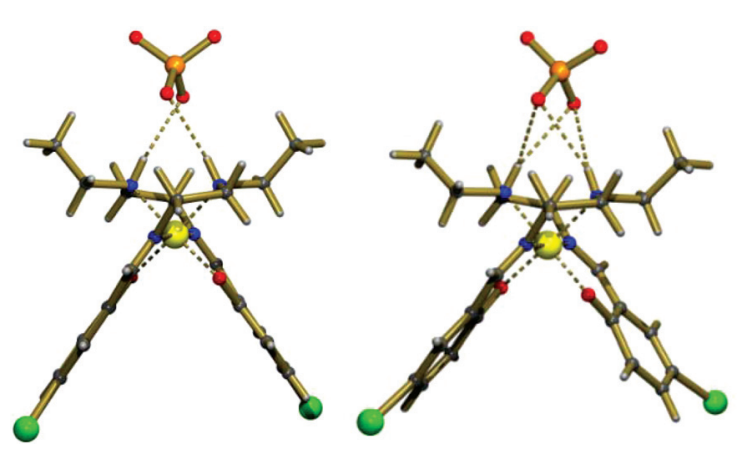

Fig. 1 Molecular structures of 1 b (left) and 1 a (right) at $125 \mathrm{~K}$ and $105 \mathrm{~K}$, respectively, showing the cation-anion hydrogen-bonded associations. The equivalent view adopted for both representations is along the line defined by the corresponding $\mathrm{C} 4$ atoms of both ligands which are eclipsed at the center, just above iron (in yellow). Grey, light grey, blue, yellow, red, orange and green ellipsoids represent $\mathrm{C}, \mathrm{H}, \mathrm{N}, \mathrm{Fe}, \mathrm{O}, \mathrm{Cl}$ and $\mathrm{Br}$ atoms (for labeled structures please refer to the ESI $\$$ ).
Table 1 Selected distances and angles in polymorphs $1 \mathbf{a}$ and $\mathbf{1 b}$. Pairs of values in the 1a column correspond to those ligands unrelated by symmetry in the cation. $\alpha$ is the angle between the planes of the aromatic rings of the ligands in the same cation

\begin{tabular}{lll}
\hline & $\mathbf{1 b}(T=125 \mathrm{~K})$ & $\mathbf{1 a}(T=105 \mathrm{~K})$ \\
\hline$a(\AA)$ & $10.3027(4)$ & $9.7817(9)$ \\
$b(\AA)$ & $14.2644(6)$ & $23.4602(19)$ \\
$c(\AA)$ & $18.1624(7)$ & $11.8961(8)$ \\
$\beta\left({ }^{\circ}\right)$ & 90 & $103.885(2)$ \\
$\mathrm{Vol} .\left(^{3}\right)$ & $2669.2(3)$ & $2650.1(4)$ \\
$\mathrm{Fe} \cdots \mathrm{O}(\AA)$ & $1.8684(2)$ & $1.8679(16) / 1.8820(15)$ \\
$\mathrm{Fe} \cdots \mathrm{N}_{\mathrm{im}}(\AA)$ & $1.9361(14)$ & $1.9302(19) / 1.9315(20)$ \\
$\mathrm{Fe} \cdots \mathrm{N}_{\mathrm{am}}(\AA)$ & $2.0340(14)$ & $2.0473(20) / 2.0566(20)$ \\
$\mathrm{N}_{\mathrm{am}} \cdots \mathrm{Cl}(\AA)$ & $3.7582(16)$ & $3.819(2) / 3.744(2)$ \\
$\mathrm{N}_{\mathrm{am}}-\mathrm{H} \cdots \mathrm{O}(\AA)$ & $3.160(2)$ & $3.230(3) / 3.240(3) 3.194(3) / 3.219(3)$ \\
$\mathrm{N}_{\mathrm{am}}-\mathrm{H} \cdots \mathrm{O}\left({ }^{\circ}\right)$ & $157.5(19)$ & $145(2) / 157(3) / 149(2) / 154(2)$ \\
$\mathrm{C} 2-\mathrm{N} 1-\mathrm{C} 3-\mathrm{C} 4\left(^{\circ}\right)$ & $-173.10(14)$ & $-169.64(20) /-172.38(20)$ \\
$\mathrm{C} 3-\mathrm{C} 4-\mathrm{N} 2-\mathrm{C} 5\left(^{\circ}\right)$ & $137.42(16)$ & $149.22(21) / 139.99(22)$ \\
$\mathrm{C} 5-\mathrm{C} 6-\mathrm{C} 7-\mathrm{O}\left(^{\circ}\right)$ & $4.7(3)$ & $-9.8(4) /-2.3(4)$ \\
$\alpha\left({ }^{\circ}\right)$ & $68.474(17)$ & $73.53(7)$ \\
& &
\end{tabular}

overall stretching of the ligand and shows that one of the ligands in 1a is more stretched (11.367 $\AA$ ), while the other is less stretched (11.264 $\AA$ ) than the corresponding symmetry related ligands in $\mathbf{1 b}(11.309 \AA)$, reflecting an overall higher asymmetry of 1a, Fig. S1 and $\mathrm{S} 2 .+$

The strongest $\mathrm{N}_{\mathrm{am}}-\mathrm{H} \cdots \mathrm{O}$ (perchlorate) hydrogen bonds are different in polymorphs $\mathbf{1 a}$ and $\mathbf{1 b}$, although the metal-ligand binding mode is the same in both polymorphs and the donor/ acceptor atoms in the hydrogen bonds are the same, as shown in Fig. 1. Thus, the cation and anion are more strongly and more rigidly bound in 1a through two independent bifurcated H-bonds (3.230(3)/3.240(3) 3.194(3)/3.219(3) $\AA$ ) than in 1b with only one bond $(3.160(2) \AA)$. The latter cation-anion associations constitute the building blocks for the overall 3D structure in both polymorphs $\mathbf{1 a}$ and $\mathbf{1 b}$. However, the cooperative weak intermolecular interactions between these building blocks are stronger in polymorph 1a, where $\mathrm{C}-\mathrm{H} \cdots \mathrm{Br}$ and $\mathrm{C}-$ $\mathrm{H} \cdots \pi$ hydrogen bonds, ${ }^{31} \pi \cdots \pi$ stacking, and $\mathrm{C}-\mathrm{Br} \cdots \pi$ halogen bonds ${ }^{32,33}$ can be found.

The 3D structure of 1a can be understood as the stacking of (100) 2D sheets of parallel zigzag chains of cation-anion associations, Fig. 2.

The cation-anion associations in these chains are only weakly bound via a weak $\mathrm{C}-\mathrm{H} \cdots \mathrm{Br}$ hydrogen bond. There are other infinite chains of cation-anion associations bound via $\mathrm{C}-\mathrm{Br} \cdots \pi$ halogen bonds running across the latter sheets along [201] (see Fig. S3 $\$$ ). In polymorph $\mathbf{1 b}$ the intermolecular interactions rely on weak $\mathrm{C}-\mathrm{H} \cdots \mathrm{O}$ hydrogen bonds. ${ }^{23}$

Distortion parameters were determined for both polymorphs. The local angular distortion of the octahedral donor $(\Sigma)$ and the dihedral angle between the two phenoxy rings $(\alpha)$ were considered and were determined for both polymorphs and are shown in Table 2 (as well as the distance between iron and the anion).

Examination of the structure and packing diagrams of compound 1a at both high and low temperatures revealed that 


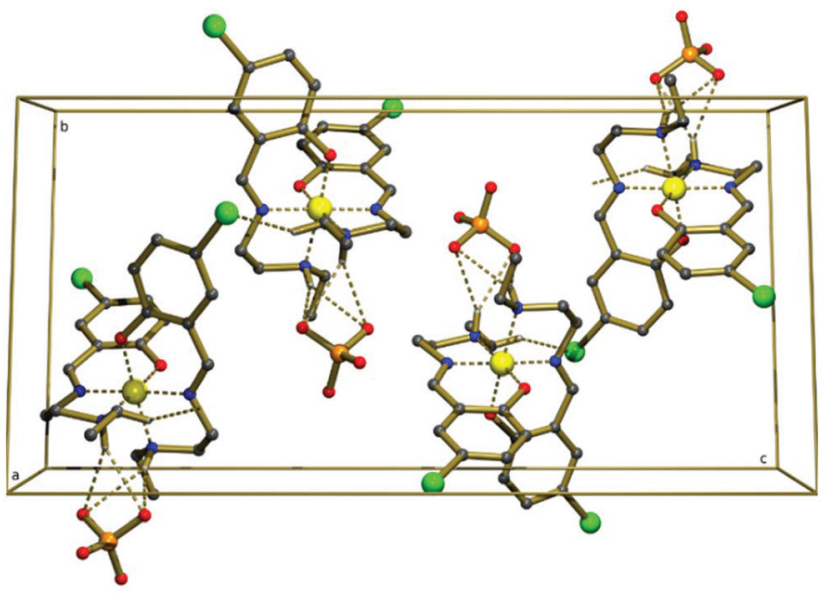

Fig. 2 Sheet of zigzag chains of weakly hydrogen-bonded cationanion associations parallel to the (001) plane in 1a. Two distinct chains are represented, one to the right and the other to the left. Hydrogen atoms are not shown, except those involved in the hydrogen bonds.

Table 2 Distortion parameters of polymorphs $1 \mathrm{a}$ and $\mathbf{1 b}$

\begin{tabular}{llllll}
\hline Polymorph & Spin state & $T / \mathrm{K}$ & $\Sigma /{ }^{\circ}$ & $\alpha /{ }^{\circ}$ & $d_{\mathrm{Fe}-\text { anion }} / \AA$ \\
\hline $\mathbf{1}^{\mathrm{a}}$ & LS & 105 & 38.1 & 73.5 & 4.919 \\
& HS & 300 & 62.8 & 79.5 & 5.048 \\
$\mathbf{1 b}$ & LS & 125 & 52.8 & 68.5 & 4.907 \\
& LS & 300 & 50.8 & 67.5 & 4.935 \\
& LS + HS & $300^{a}$ & 39.9 & 73.7 & 4.916 \\
& LS & $250^{a}$ & 52.6 & 67.7 & 4.929
\end{tabular}

${ }^{a}$ Structures determined post-warming up the crystals to $370 \mathrm{~K}$.

both structures are not distinctively different, Table S1 and Fig. S4. In the high temperature structure, the crystals are in the monoclinic space group $P 2_{1} / c$ with bond lengths around the metal center typical of $\mathrm{HS}$ Fe(III). The stronger interactions attributed to the hydrogen bonded anion-cation associations are still present. As observed for $\mathbf{1 a}$ at low temperature, $\mathrm{C}-\mathrm{H} \cdots \mathrm{Br}$ and $\mathrm{C}-\mathrm{H} \cdots \pi$ hydrogen bonds, $\pi \cdots \pi$ stacking, and $\mathrm{C}-\mathrm{Br} \cdots \pi$ halogen bonds can be found.

\section{Magnetic studies}

The variable-temperature magnetic susceptibility curve for 1a obtained from magnetization measurements between 10 and $300 \mathrm{~K}$ at $5 \mathrm{~K} \mathrm{~min}^{-1}$ both in the cooling and heating modes is shown in Fig. 3.

An almost complete and abrupt spin transition in the range of $165-175 \mathrm{~K}$, with a $T_{1 / 2}$ of $172 \mathrm{~K}$, can be deducted from the $\chi_{\mathrm{M}} T$ vs. $T$ curve. The magnetization curve recorded at both lower scan rates $\left(2 \mathrm{~K} \mathrm{~min}^{-1}\right)$ and smaller temperature steps (each $0.5 \mathrm{~K}$ ) reveals a small $1 \mathrm{~K}$ hysteresis window between $169 \mathrm{~K}$ and $172 \mathrm{~K}$, inset of Fig. 3. The $\chi_{\mathrm{M}} T$ values at $10 \mathrm{~K}$ and $300 \mathrm{~K}$ are $0.466 \mathrm{~cm}^{3} \mathrm{~K} \mathrm{~mol}^{-1}$ and $4.04 \mathrm{~cm}^{3} \mathrm{~K} \mathrm{~mol}^{-1}$, respectively, and the cooling and heating curves are superimposable. This magnetic behavior is completely different from the one exhibited by polymorph $\mathbf{1} \mathbf{b}^{23}$ where a large hysteresis window

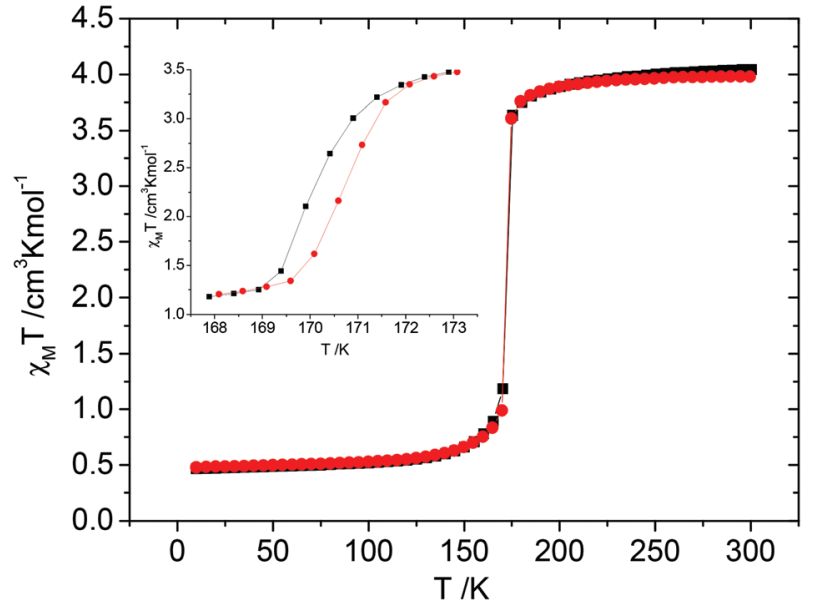

Fig. 3 Temperature dependent magnetic measurements for 1a (inset: magnetization curve recorded at $2 \mathrm{~K} \mathrm{~min}^{-1}$ and $0.5 \mathrm{~K}$ temperature steps).

(30 K) at room temperature was found. This is also an indication that compound 1a corresponds to a new polymorph of $\left[\mathrm{Fe}(5 \text {-Br-salEen })_{2}\right] \mathrm{ClO}_{4}$.

Compound 1a was further characterized by ${ }^{57} \mathrm{Fe}$ Mössbauer spectroscopy both at $78 \mathrm{~K}$ and room temperature, Fig. 4.

The spectrum at $78 \mathrm{~K}$ presents a very pronounced line asymmetry, similar to what was observed and investigated for $\mathbf{1 b} .^{19}$ In line with our previous findings, this asymmetry should be due to the relatively long paramagnetic relaxation times of the $\mathrm{Fe}(\mathrm{III})$ center when compared to the ${ }^{57} \mathrm{Fe}$ nuclear Larmor precession time. Assuming the same behavior, the spectrum at $78 \mathrm{~K}$ was well fitted by a single quadrupole doublet with hyperfine parameters typical of LS Fe(III) (isomer shift $\delta=0.22(1)$ mm s${ }^{-1}$; quadrupole splitting $\Delta E_{\mathrm{Q}}=2.93(1) \mathrm{mm} \mathrm{s}^{-1}$ ). In agreement with the magnetization behavior, the spectrum at $290 \mathrm{~K}$ is very different from the one obtained for $\mathbf{1 b}$. As deduced from the $\chi_{\mathrm{M}} T$ value at $290 \mathrm{~K}$ (Fig. 3), 1a is essentially in the HS state. The Mössbauer spectrum is rather broad but clearly

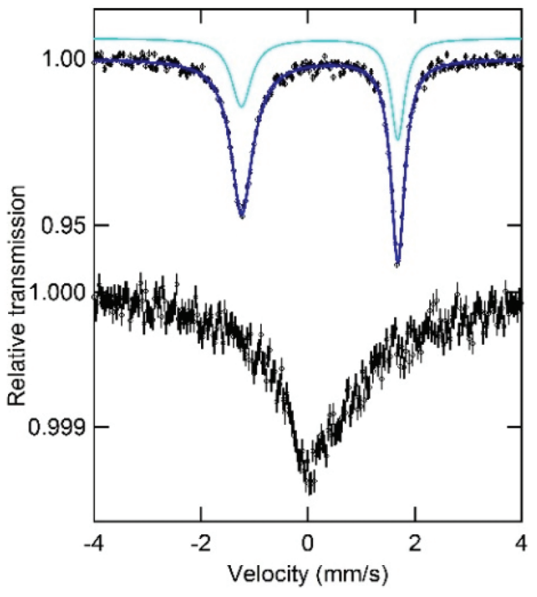

Fig. $4{ }^{57} \mathrm{Fe}$ Mössbauer spectra of 1a, collected at $78 \mathrm{~K}$ (top) and $290 \mathrm{~K}$ (bottom). 
different from that obtained at $78 \mathrm{~K}$, although a small contribution of the LS component cannot be disregarded. In fact, the Mössbauer spectrum at $290 \mathrm{~K}$ suggests rapid spin-state interconversion between HS and LS states, when compared to the ${ }^{57}$ Fe Mössbauer time scale $\left(>107 \mathrm{~s}^{-1}\right) .{ }^{34}$

\section{Differential scanning calorimetry (DSC)}

Polymorph 1a was investigated by DSC over the range 150-250 $\mathrm{K}$ on warming and cooling at $10 \mathrm{~K} \mathrm{~min}^{-1}$, Fig. 5.

On warming, an endothermic peak characteristic of a first order phase transition was detected at $T_{\max } \uparrow=172.5 \mathrm{~K}$. This temperature is in very good agreement with the transition temperature detected by SQUID measurements. On cooling, an endothermic peak is observed at $172.8 \mathrm{~K}$ confirming the results obtained for the magnetization measurements. Surprisingly, a small peak characteristic of a first order transition is detected at $174 \mathrm{~K}$. Repeated measurements confirmed on warming the peak at $172.5 \mathrm{~K}$ and on cooling the presence of a major peak at $172 \mathrm{~K}$, while the small peak became a shoulder (see Fig. S5 $\$$ ). To try to elucidate the nature of the second small peak, SQUID measurements were performed on a sample of polymorph 1a using different scan rates and smaller temperature intervals (0.5 K), Fig. S6. $\ddagger$ However, an envisioned stepped first-order transition is not observed for the slower scan rate magnetization studies. The enthalpy and entropy values were evaluated as $\Delta H$ $=6.09 \mathrm{~kJ} \mathrm{~mol}^{-1}$ and $\Delta S=35.3 \mathrm{~J} \mathrm{~mol}^{-1} \mathrm{~K}^{-1}$. The entropy change is much higher than the one accounting for an electronic contribution only $\left(\Delta S_{\mathrm{el}}=9.13 \mathrm{~J} \mathrm{~mol}^{-1} \mathrm{~K}^{-1}\right)$ allowing to derive the vibrational entropy associated with the spin conversion $\Delta S_{\text {vib }}=$ $26.17 \mathrm{~J} \mathrm{~mol}^{-1} \mathrm{~K}^{-1}$. This vibrational entropy value calls for a large modification of vibrational modes in the solid.

The DSC measurements together with the structural data suggest that vibrational coupling throughout the crystalline lattice is responsible for the major changes in the magnetic profile. The small rearrangements in the structure and the changes in the bond length between the HS and LS structures are highly sensitive to the vibrational coupling of the lattice, thus the abrupt spin crossover for $\mathbf{1 a}$.

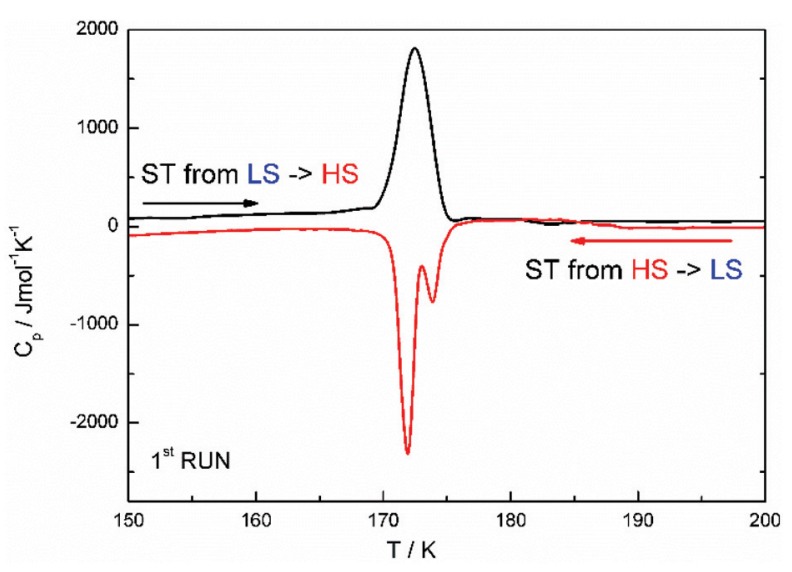

Fig. 5 Plot of heat capacity vs. $T$ for $1 \mathrm{a}$ on warming and cooling at $10 \mathrm{~K}$ $\mathrm{min}^{-1}$, over the range of $150 \mathrm{~K}$ and $200 \mathrm{~K}$.
Serendipitously, magnetization studies of a freshly prepared sample displayed a profile comprising the mixture of the magnetic profiles of the two polymorphs, Fig. S7.\$ This new sample was obtained following the same experimental conditions used to prepare 1a (reaction carried out at room temperature and crystallization by slow solvent evaporation also at room temperature). This finding suggested that slight changes in the reaction temperature, crystallization or solvent evaporation might be sufficient to condition the formation of each polymorph. Thus, we wondered whether each polymorph might be selectively obtained by changing the temperature of the reaction, the temperature of crystallization or the rate of solvent evaporation.

\section{Polymorph selectivity studies}

Polymorphs 1a and 1b were indeed selectively obtained by changing experimental parameters such as the reaction temperature, crystallization temperature and solvent evaporation rate. A comprehensive study was performed to determine which parameters conditioned the polymorph obtained, Table 3. Slow evaporation refers to, at least, 3 days until crystal formation, while fast evaporation crystals formed in less than $24 \mathrm{~h}$. For all solids obtained, the composition was determined by elemental analysis and the magnetic profiles by magnetization measurements.

The syntheses performed at $-90^{\circ} \mathrm{C}$ (i) and reflux conditions $\left(65{ }^{\circ} \mathrm{C}-\mathrm{vi}\right)$ gave solids that precipitated out of solution during the reaction, and the solids were filtered and it was shown that 1a was formed for both reaction conditions. These results show that the reaction temperature seems not to affect which polymorphic phase formed from the reaction. The filtrates of the reactions mixtures were crystallized at room temperature for the reaction at $-90{ }^{\circ} \mathrm{C}$ (ii) and at $40{ }^{\circ} \mathrm{C}$ for the reflux reaction (vii) and the crystals obtained in less than $24 \mathrm{~h}$ were filtered and their magnetic behavior was measured. Magnetization studies confirmed that both compounds were obtained in the form of $\mathbf{1 b}$. These findings show that the reaction temperature does not determine which polymorph of $\mathbf{1}$ is formed. The filtrate of (vii) yielded a new batch of crystals (viii) that, unexpectedly, showed a preference for 1a. This was quite

Table 3 Experimental conditions for the synthesis of polymorphs 1a and $1 \mathrm{~b}$

\begin{tabular}{|c|c|c|c|c|}
\hline & \multicolumn{2}{|c|}{ Temperature $/{ }^{\circ} \mathrm{C}$} & \multirow[b]{2}{*}{ Crystallisation rate } & \multirow[b]{2}{*}{ Polymorph } \\
\hline & Reaction & Crystallisation & & \\
\hline i & -90 & - & Fast & $1 a^{a}$ \\
\hline ii & -90 & rt & Fast & $1 b$ \\
\hline iii & -78 & $\mathrm{rt}$ & Slow & $1 \mathrm{a}$ \\
\hline iv & rt & $\mathrm{rt}$ & Slow & $1 \mathrm{a}$ \\
\hline $\mathrm{v}$ & rt & $\mathrm{rt}$ & Fast & $1 b$ \\
\hline vi & Reflux & - & Fast & $1 \mathrm{a}$ \\
\hline vii & Reflux & 40 & Fast & $1 \mathrm{~b}$ \\
\hline viii & Reflux & 40 & Slow & $1 a^{b}$ \\
\hline ix & Reflux & 40 & Slow & $1 \mathrm{a}$ \\
\hline
\end{tabular}

${ }^{a}$ With impurities. ${ }^{b}$ Crystallisation of the filtrate of vii. 
surprising since at this point only two reaction conditions, the reaction temperature and the crystallization temperature, were being controlled, and suggested that the rate of solvent evaporation should also be considered, since the speed of crystal formation could have an effect on the polymorph preference. The most striking feature was obtained for ix, which shows that a slow crystallization favors $\mathbf{1 a}$, while for fast crystallization $\mathbf{1 b}$ is formed, the crystallization temperature being possibly irrelevant for the control of the polymorphic species formed. Further confirmation came from an additional experiment, where the synthesis was carried out under reflux conditions, the crystallization at $40{ }^{\circ} \mathrm{C}$ and the solvent evaporation was slow (viii). Polymorph 1a was the main obtained product (90\%) with a remaining $10 \%$ of $\mathbf{1 b}$ identified by the magnetization studies. Another experiment that corroborates the previous evidence is the synthesis performed at $-78^{\circ} \mathrm{C}$ followed by slow crystallization at room temperature (iii) that preferentially gave 1a. At this point, the influence of the reaction and crystallization temperatures on the polymorph preference can be excluded, the crystallization rate being the main and determining parameter to be taken into consideration. Two experiments with compounds synthesized and crystallized at room temperature with different crystallization rates, (iv) and (v), gave $\mathbf{1 a}$ for the slow process and $\mathbf{1 b}$ for the fast crystallization, reinforcing the previous conclusions.

\section{Conclusions}

$\left[\mathrm{Fe}(5-\mathrm{Br}-\mathrm{salEen})_{2}\right] \mathrm{ClO}_{4}$ crystallizes as two different polymorphs, which can be obtained managing a selective control of the synthesis method. The rate of crystallization was found to be the determining factor. The new polymorph $\mathbf{1 a}$ is built from the same cation and anion, but the $\mathrm{N}_{\mathrm{am}} \mathrm{H} \cdots \mathrm{O}$ (perchlorate) hydrogen bond network linking them is different, providing a larger binding energy in 1a. These features are observed both in the low and in the high temperature structures. Both polymorphs experience spin crossover, but the magnetization profiles differ significantly, 1a displaying an abrupt and complete spin transition, detected by different methods, and $\mathbf{1 b}$ exhibiting hysteresis, as reported before. Such a different behavior is explained by the cooperative effect and nature of the intermolecular interactions between the hydrogen bonded cationanion associations, which are more diverse and stronger for polymorph $\mathbf{1 a}$.

\section{Conflicts of interest}

The authors declare no conflicts of interest.

\section{Acknowledgements}

We thank Fundação para a Ciência e a Tecnologia for financial support (PTDC/QEQ-QIN/3414/2014, UID/MULTI/00612/2013, UID/MULTI/04046/2013) and fellowship to PNM (SFRH/BPD/
73345/2010). We also thank the Fonds National de la Recherche Scientifique-FNRS for a PDR (T.0102.15) and WBI for a stipendium of excellence allocated to M. M. D. The COST actions CM1305 (ECOSTBio) and CA15128 (MOLSPIN) are greatly acknowledged.

\section{References}

1 D. Braga and F. Grepioni, Making crystals by design: methods, techniques and applications, Wiley-VCH, 2007.

2 P. Gütlich, A. B. Gaspar and Y. Garcia, Beilstein J. Org. Chem., 2013, 9, 342-391.

3 J. Tao, R. J. Wei, R. B. Huang and L. S. Zheng, Chem. Soc. Rev., 2012, 41, 703-737.

4 E. Collet, M. L. Boillot, J. Hebert, N. Moisan, M. Servol, M. Lorenc, L. Toupet, M. Buron-Le Cointe, A. Tissot and J. Sainton, Acta Crystallogr., Sect. B: Struct. Sci., 2009, 65, 474-480.

5 W. Phonsri, C. G. Davies, G. N. L. Jameson, B. Moubaraki and K. S. Murray, Chem. - Eur. J., 2016, 22, 1322-1333.

6 I. Šalitroš, L. Pogány, M. Ruben, R. Boča and W. Linert, Dalton Trans., 2014, 43, 16584-16587.

7 J.-F. Létard, P. Guionneau, L. Rabardel, J. A. K. Howard, A. E. Goeta, D. Chasseau and O. Kahn, Inorg. Chem., 1998, 37, 4432-4441.

8 J.-F. O. Létard, G. Chastanet, O. Nguyen, S. Marcén, M. Marchivie, P. Guionneau, D. Chasseau and P. Gütlich, Monatsh. Chem., 2003, 134, 165-182.

9 M. Marchivie, P. Guionneau, J. F. Létard and D. Chasseau, Acta Crystallogr., Sect. B: Struct. Sci., 2003, 59, 479-486.

10 I. Šalitroš, O. Fuhr, A. Eichhöfer, R. Kruk, J. Pavlik, L. Dlháň, R. Boča and M. Ruben, Dalton Trans., 2012, 4117, 1477-9226.

11 S. Mitra, C. Raston and A. White, Aust. J. Chem., 1978, 31, 547.

12 G. S. Matouzenko, A. Bousseksou, S. Lecocq, P. J. van Koningsbruggen, M. Perrin, O. Kahn and A. Collet, Inorg. Chem., 1997, 36, 5869-5879.

13 A. L. Thompson, A. E. Goeta, J. A. Real, A. Galet and M. C. Muñoz, Chem. Commun., 2004, 1390-1391.

14 D. L. Reger, J. R. Gardinier, M. D. Smith, A. M. Shahin, G. J. Long, A. Leila Rebbouh and F. Grandjean, Inorg. Chem., 2005, 44, 1852-1866.

15 C.-F. Sheu, S.-M. Chen, G.-H. Lee, Y.-H. Liu, Y.-S. Wen, J.-J. Lee, Y.-C. Chuang and Y. Wang, Eur. J. Inorg. Chem., 2013, 2013, 894-901.

16 W. Kaszub, M. B. Le Cointe, M. Lorenc, M. L. Boillot, M. Servol, A. Tissot, L. Guérin, H. Cailleau and E. Collet, Eur. J. Inorg. Chem., 2013, 2013, 992-1000.

17 S. Hayami, D. Urakami, Y. Yamamoto, K. Kato, Y. Kojima, S. Nakashima and K. Inoue, Chem. Lett., 2010, 39, 328-329.

18 K. Takahashi, T. Sato, H. Mori, H. Tajima, Y. Einaga and O. Sato, Hyperfine Interact., 2012, 206, 1-5.

19 C. Y. Wang, C.-F. Sheu, C.-H. Shih, K. Sugimoto, B.-M. Cheng, M. Takata and Y. Wang, Chem. Commun., 2012, 4848461, 5685-5800. 
20 C.-F. Sheu, S.-M. Chen, S.-C. Wang, G.-H. Lee, Y.-H. Liu and Y. Wang, Chem. Commun., 2009, 7512-7514.

21 W. Ostwald, Phys. Chem., 1897, 22, 289-330.

22 P. N. Martinho, A. I. Vicente, S. Realista, M. S. Saraiva, A. I. Melato, P. Brandão, L. P. Ferreira and M. de D. Carvalho, J. Organomet. Chem., 2014, 760, 48-54.

23 A. I. Vicente, A. Joseph, L. P. Ferreira, M. de Deus Carvalho, V. H. N. Rodrigues, M. Duttine, H. P. Diogo, M. E. Minas da Piedade, M. J. Calhorda and P. N. Martinho, Chem. Sci., 2016, 7, 4251-4258.

24 A. Rotaru, M. M. Dîrtu, C. Enachescu, R. Tanasa, J. Linares, A. Stancu and Y. Garcia, Polyhedron, 2009, 28, 25312536.

252007 Bruker SAINT-plus, Bruker AXS Inc., Madison, Wisconsin, USA, 2007.

26 SADABS, Bruker AXS Inc., Madison, Wisconsin, USA, 2008.

27 G. M. Sheldrick, Acta Crystallogr., Sect. C Struct. Chem., 2015, 71, 3-8.
28 C. F. Macrae, P. R. Edgington, P. McCabe, E. Pidcock, G. P. Shields, R. Taylor, M. Towler and J. van de Streek, J. Appl. Crystallogr., 2006, 39, 453-457.

29 A. L. Spek, Acta Crystallogr., Sect. D Biol. Crystallogr., 2009, 65, 148-155.

30 P. J. van Koningsbruggen, H. Oshio and Y. Maeda, Top. Curr. Chem., 2004, 233, 259-324.

31 M. J. Calhorda and P. J. Costa, Weak Hydrogen Bonding, in Comprehensive Inorganic Chemistry II, ed. J. Reedijk and K. Poeppelmeier, Elsevier, Oxford, vol. 9, 2013, pp. 341-357.

32 I. Seung Youn, D. Yeon Kim, W. Jong Cho, J. L. Marie Madridejos, H. Myoung Lee, M. Kołaski, J. Lee, C. Baig, S. Koo Shin, M. Filatov and K. S. Kim, J. Phys. Chem. A, 2016, 120, 9305-9314.

33 H. Wang and W. J. Jin, Acta Crystallogr., Sect. B: Struct. Sci., Cryst. Eng. Mater., 2017, 73, 210-216.

34 M. Nihei, T. Shiga, Y. Maeda and H. Oshio, Coord. Chem. Rev., 2007, 251, 2606-2621. 